\title{
Pathologies of a Glass Building Envelope that Affect Durability and Comfort
}

\author{
Susana Santamaria-Fernandez ${ }^{1}$, Arritokieta Eizaguirre-Iribar ${ }^{2}$ and Xabier Olano- \\ Azkune $^{3}$
}

${ }^{1}$ Structural Safety Lab, Industry Area, Lab Services Division, TECNALIA, Basque Research and Technology Alliance (BRTA), Area Anardi 5, 20730-Azpeitia, Spain, susana.santamaria@tecnalia.com

${ }^{2}$ Fire Safety Lab, Industry Area, Lab Services Division, TECNALIA, Basque Research and Technology Alliance (BRTA), Area Anardi 5, 20730-Azpeitia, Spain, arritokieta.eizaguirre@tecnalia.com

${ }^{3}$ Fire Safety Lab, Industry Area, Lab Services Division, TECNALIA, Basque Research and Technology Alliance (BRTA), Area Anardi 5, 20730-Azpeitia, Spain, xabier.olano@tecnalia.com

\begin{abstract}
The durability of materials used in buildings has been widely studied and, in many cases, there are standards to assess it. However, studies on how pathologies affect the durability and comfort of the building users are not so common. The aim of this article is to explain different pathologies of the building envelope, considering glass as its main element and to analyze the causes of those pathologies, agents involved, and how they have affected durability. For that purpose, different cases of pathologies were analyzed on-site, both during the construction process and during the final use of the building. The effects of the different pathologies were also assessed. In each case, the technical data sheets available of the materials involved and the information on the design and the expected performance of the constructive solution were compiled. In some cases, the pathologies had caused an irreversible damage, so, the solution had to be drastic; while in other cases, they were detected early enough to propose remedial actions without affecting the final durability of the building. After having analyzed the different cases, the agents causing the pathology or those responsible for it and the phase in which the pathology occurred were identified. As a result, remedial actions were proposed to avoid the generation of pathologies during the design, construction and maintenance processes that affect the durability of the building and their user's comfort.
\end{abstract}

Keywords: Glass, Pathology, Sealant, Coating, Durability.

\section{Introduction}

Since the industrial breakthroughs that allowed massive, high-quality production of glass for building in the 1960s, large glazed buildings have proliferated and along with them their associated pathologies. Additionally, the improvement of thermal performance of insulated glass units (from now on IGU) due to the importance of energy efficiency have resulted in premature failures in several cases (Hubbs et al., 2015). Accordingly, studies on failure cases have also increased in the literature in order to understand the reasons and effects of glass failures (Honfi et al., 2014; Loughran, 2003).

The pathologies of a glazed envelope may be of different natures. Glass breakage is one of the most known failure and have been widely studied using qualitative and quantitative methods (Overend et al., 2007). However, there are other pathologies (such as sealing failure, yellowness or delamination) that have a direct impact on the durability of the building, since they affect the 
functionality of the building and/or the comfort of the users. It should be borne in mind that the pathologies in this building element usually have the added complexity that the number of materials and elements that form the envelope solution are many and of a very different nature and function.

The pathologies of a glass building envelope can occur due to the following causes: chemical incompatibility, manufacturing failure/error or because of a product is not suitable for its intended use.

In a building envelope there are a lot of different organic materials and it is complicated to verify the chemical compatibility between all of them. In extreme cases it is not even necessary that both materials are in physical contact for a failure to occur.

Manufacturing failures, such an incorrect choice of materials or unsuitable manufacturing times and conditions, may also create pathologies. They are common in innovative and unique products or solutions as there is no previous experience.

Finally, an unsuitable glass product can also cause pathologies. The product is correctly manufactured, but its intended use has not been taken into account and this leads to a pathology, i.e. not all glass products can be used in all situations. For example, the building envelope may be subject to adverse environmental conditions that were not considered at the design stage.

Therefore, a pathology can occur in any of the following stages of the building work: design, manufacturing, assembling, on-site execution and while it is in service. In this article, we will only focus on the failure mechanisms that appears in the service period. All these failures have a direct impact on the durability of the building envelope. On the one hand, directly on the durability of the materials and on the other hand, indirectly on the durability of the building
since the thermal, acoustic and optical performance are affected.
In the following sections we will give notions and andlyze dach of them deeper through real
case studies.

\section{Sealing Faillure}

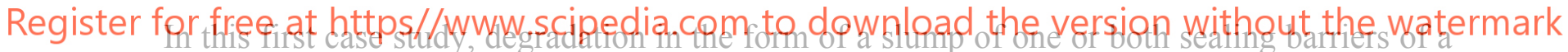
IGU is noted (Figure 1). This pathology occurs in an office building with a large glazed surface that is two years old. The construction of all the glazing in the building is unique, large-format double insulating glass units filled with argon gas formed both externally and internally by laminated glass.
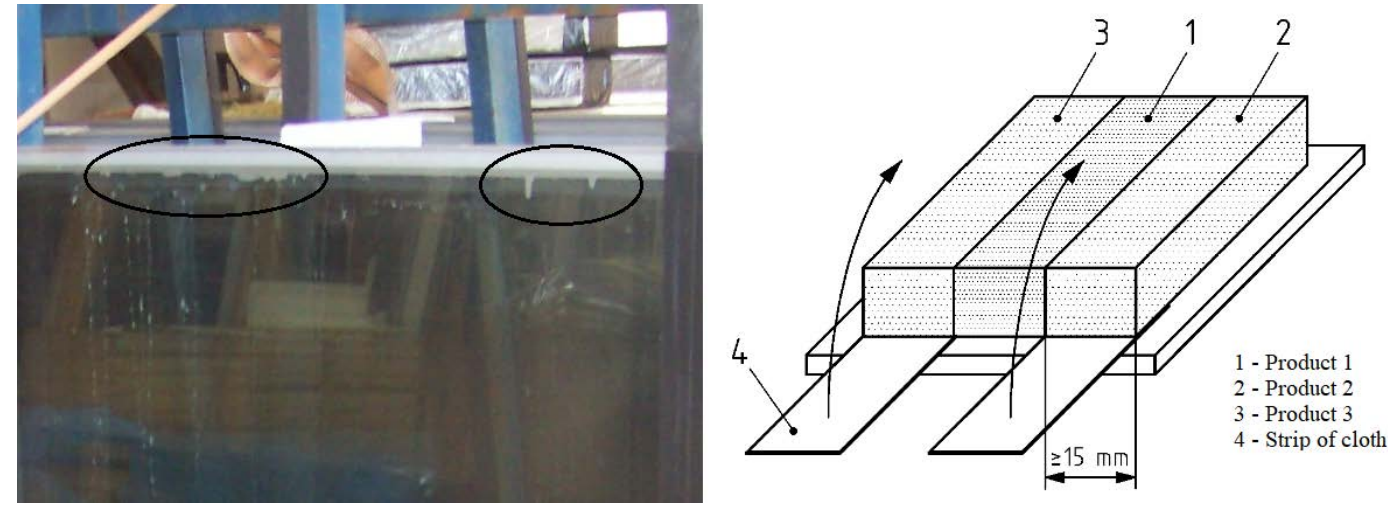

Figure 1. Sealant flowing (left) and test specimen for the chemical incompatibility test (right). 
Degradation is detected in discrete areas of some of the IGUs. The concern with this pathology is firstly, the possible detachment of the outer sheet and its subsequent fall and secondly, if the property of thermal insulation is still preserved.

\subsection{On-Site Inspection}

When analyzing the units with pathology and their situation in the building, no pattern was detected due to their location in areas most exposed to solar radiation and therefore to a higher temperature. No water leakage was detected in the building envelope, i.e. the drainage system of the curtain wall seemed to be working correctly. All the glass units were exposed to equivalent UV radiation except for the differences due to the orientation of the building, however, no pattern showed that the failure was due to the orientation, height or degrees of exposure of those units and the pathology only appeared in some of them. Therefore, the influence of the environmental conditions such as temperature, humidity and radiation was dismissed early in the on-site inspection process.

When degradation of a sealant is observed, it is necessary to analyze which agents may be producing that degradation. Several IGUs were dismantled from the building and sent to the laboratory for a deep analysis, as only the on-site inspection couldn't lead to a clear conclusion.

\subsection{Laboratory Analysis}

Once the samples were received in the laboratory, one of them was disassembled. Both sheets of glass were separated, and it was verified that the sealant was the one gttacked. In this case,
the degraded sealant was that of the first sealing barrier.
After this, all the polymeric products contained in the curtain wall were identified and
gathered, such as sealants, adhesives, gaskets, supporting blocks... regardless of being in direct
contact with each other or not. After this, sets of specimens containing adjacent materials yere subjected to a chemical compatibility test using the UV method in accordance with section 7 of for $15434: 2007+$ A $1: 2010$ Glass in building - Product standard for structural and/or pl tra-violet resistant sealant (10) use with structural sealant glazing and/or IGUs with exposed seals).

For performing the ageing, a laboratory weathering instrument ATLAS weather-ometer model Ci3000+ was used. The test specimens (Figure 1) were prepared with each two of the materials under study and they were exposed to UV solar radiation (by xenon lamps) for 504 hours and at $60{ }^{\circ} \mathrm{C}$ temperature. After this UV exposure a peeling test was performed by means of strips of cloth or with cuts. A positive result in the test means that no visual discoloration appears and that no adhesive breakage occurs during the peeling tests.

After completing the compatibility test on the different combinations of adjacent materials, it was verified that the inner sealing barrier and the weathertightness gasket were highly incompatible.

Additionally, to this analysis, the building owner has made several measurements of the argon gas content of the glazing units, regardless degradation was present or not. Those measurements did not register a significant gas leakage on the units and a total detachment of the external glass pane has been dismissed up to now. The owner is performing regular controls to check the evolution of the pathology. 


\section{Luminous Transmittance Variation}

The pathology studied in this second case occurred on two floors of a building that had not yet been occupied. There was no furniture or equipment that could alter human visual perception in any of the floors. However, a difference was noted by the owners in the perceived luminous radiation coming to the inside in each of the floors.

It was an office building with several floors where refurbishment was planned to be performed floor by floor. Refurbishment was integral, so affecting to the change of building envelope and interior furniture or equipment.

Refurbishment of the initial floor consisted in changing the carpentry and glazing of the complete envelope and after finishing there, works started in a new floor non adjacent to that first one.

First step of the pathology evaluation consisted in studying the type of glazing requested and checking delivery notes for the glazing of both floors. After that, an on-site visual inspection was carried out for a first approach. It was not so easy to visually quantify the difference in visual perception of the solar radiation, due to the great height gap between floors. This height gap means that shading due to adjacent buildings differs significantly and the influence on each floor is hard to quantify.

Therefore, the decision to remove two glazing units, one per each floor, and to measure their luminous and solar characteristics in the laboratory, was taken. IGUs were completely dismantled and luminous and solar transmittance and reflectance of all glazing panes were

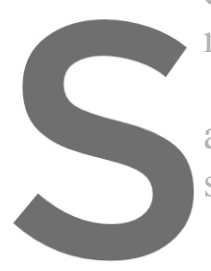
measured, in order to ched

The IGU was compose a thermally toughened spectrophotometer UY-
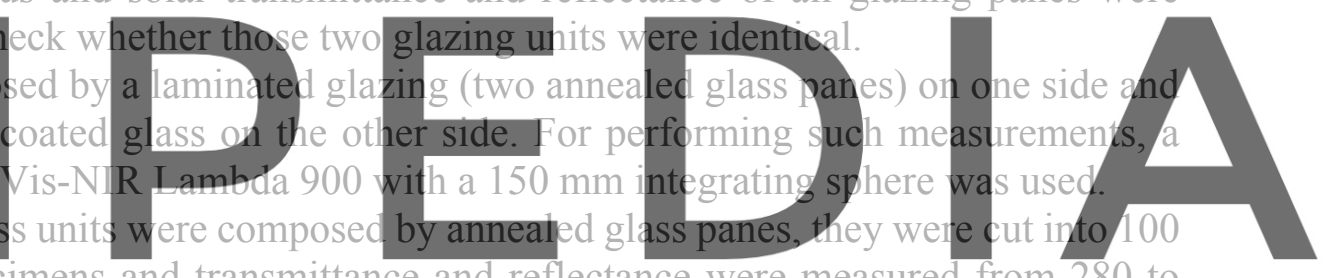

$\mathrm{mm} \times 100 \mathrm{~mm}$ test specimens and transmittance and reflectance were measured from 280 to

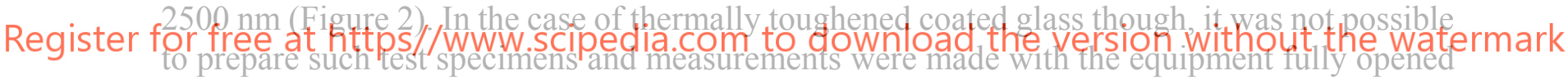
and the surrounding of the lab prepared to avoid external radiation getting inside.

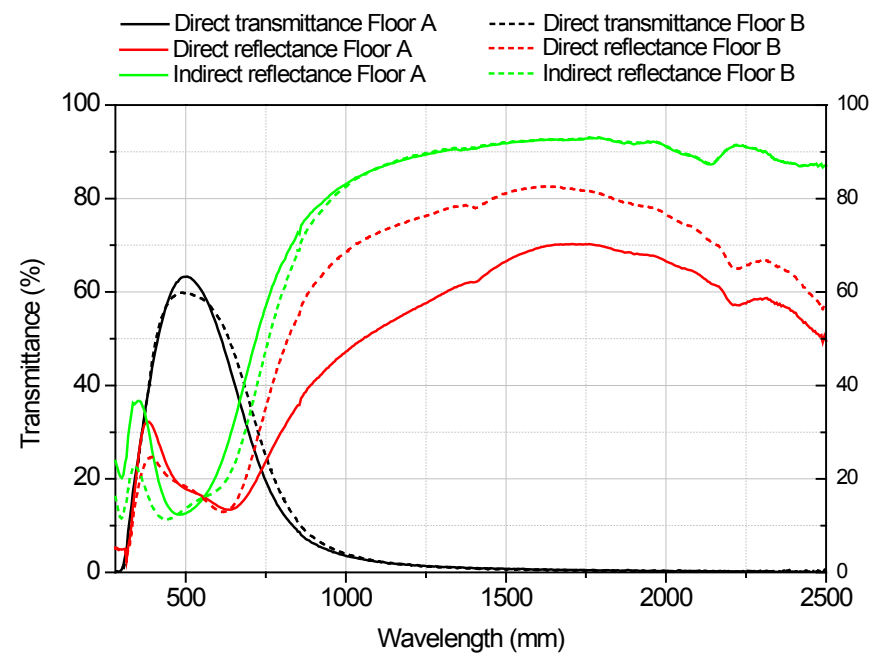

Figure 2. Transmittance and reflectance spectra of the coated glass. 
After finishing the lab measurements, we noticed that laminated glass panes for both glazing units were the same but coated glass panes were not identical. Even though they were similar, differences were enough to be perceived by the human eye.

Considering manufacturing tolerances in the luminous/solar transmittance and/or reflectance, it could be concluded that both coated glass panes were not the same product.

Glass coatings are metallic oxides depositions that affect to the luminous, thermal or solar properties of the glass panes. Some coatings do not bear the thermal toughening process, so coatings are usually designed to provide similar properties, both for a toughened and a nontoughened version.

With the described measurements and collaboration from the manufacturer, we reached the conclusion that there was a manufacturing error, meaning that a coating not designed for the thermal toughening process, had been tempered by mistake.

\section{Yellowness and Delamination}

Pathologies are different for the sandwich products composed of glass and materials of different nature. An on-site inspection of the building of the third case showed colour change in glass products. Detachment of the exterior glass sheet was also detected in some cases. The inspection revealed that two types of glass solution with a similar external appearance had been used, one placed on the façade and the other on a sloping roof.

This case study refers to a semi-public building that has been in use for more than 10 years.

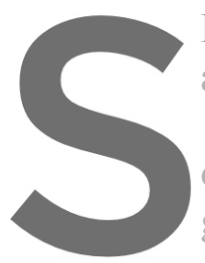
For the study of patholog along with stocked glass

One of the solutions of an unknown nature, glass pane. The second adhered to a pane of marble, which was in turn glued to an aluminium honeycomb panel.

Since the conditions of temperature and water presence are usually very different on the

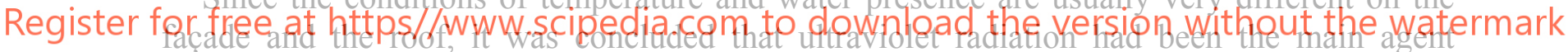

responsible for degradation. Nevertheless, the other agents - temperature and water in this casehad aiso played their role.

The durability of the material was evaluated by exposing two samples to ultraviolet radiation: a glass-marble-glass composition piece without defects and a glass-marblehoneycomb composition piece with colour degradation. Half of each piece was covered to avoid the degradation of that area. The test was carried out according to the procedure described in method A of section 7 of the standard EN ISO 12543-4:2011 Glass in building. Laminated glass and laminated safety glass. Part 4: Test methods for durability.

The test consisted in subjecting part of each panel to 2,000 hours of radiation. For this purpose, the panels were placed at $1,100 \mathrm{~mm}$ from 16 OSRAM ULTRAVITALUX lamps that formed an area of $1 \mathrm{~m} \times 1 \mathrm{~m}$. The radiation level on the panels was $(900 \pm 100) \mathrm{W} / \mathrm{m}^{2}$. The radiation source used emits a spectrum similar to solar radiation and its spectral characteristics are as follows: UVB $(280-315 \mathrm{~nm}) 3 \% \pm 1 \%$; UVA $(315-380 \mathrm{~nm}) 8 \% \pm 1 \%$; Visible light (380 - $780 \mathrm{~nm}) 18 \% \pm 1 \%$; IRA (780 - $1400 \mathrm{~nm}) 24 \% \pm 2 \%$; IRB (1400 - $2600 \mathrm{~nm}) 27 \% \pm 4 \%$; and IRC (>2600 nm) $20 \% \pm 3 \%$.

Three different areas of the exposed zone of each panel were selected and three luminous 
reflectance measurements were made in each of them before and after the ageing. The luminous reflectance spectrum between $360 \mathrm{~nm}$ and $740 \mathrm{~nm}$ was measured using Minolta model CM2600d spectrocolorimeter in incidence $d / 8^{\circ}$. The colour coordinates $L^{*} a^{*} b^{*}$ for the observer at $10^{\circ}$ and the illuminant D65 were calculated from the reflectance spectrum according to CIE76. Afterwards, the $\mathrm{L}^{*} \mathrm{a}^{*} \mathrm{~b}^{*}$ average colour coordinates of each area were determined and the $\Delta \mathrm{E}^{*}$ ab colour difference between the initial and final situation was calculated. The panels were also inspected for additional failures.

After 2,000 hours of exposure to simulated solar radiation, a considerable change in colour was observed between the exposed and unexposed areas of both panels (Figure 3). In the case of the glass-marble-glass composition, the difference in colour in the three selected areas before and after aging was less than 2.3 and in the case of the glass-marble-honeycomb composition the difference was greater than 2.3 .
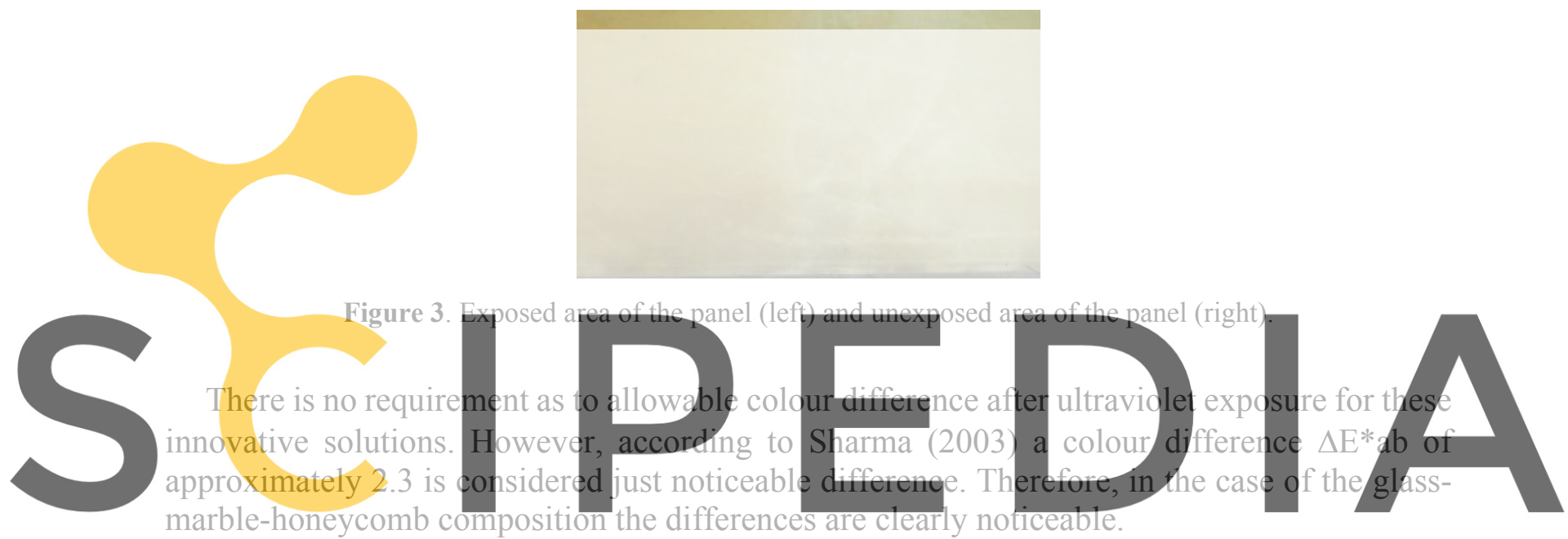

At the same time, the nature of the adhesives was analyzed by comparing the infrared spectra

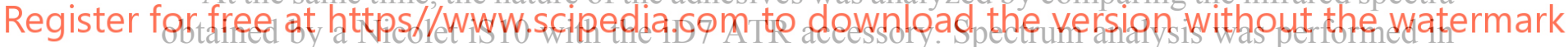

transmittance mode, with 16 scans. Additionally, a thermogravimetric analysis was performed

with a TG-DTA92 thermobalance in order to check the proportion of the different components. It is concluded that the nature of all adhesives used between glass and marble is the same regardless of the composition of the panel.

During the inspection of the building it was observed that the roof area was more degraded than the façade area. Even so, it is proved that in both cases the solution chosen was not suitable for the intended use. In order to avoid this pathology that directly affects durability, the suitability of both solutions should have been verified in the design implementation phase, considering the environmental conditions to which they would be exposed.

\section{Interlayer Failures}

In line with the latter case, bubbles, cloudiness, delamination or colour variations can be appeared in laminated glass compositions. The compositions of glass-glass with some other material embedded in the organic interlayer that joints both glasses are especially prone to failure. Therefore, those compositions are cases to be studied. In this regard, there are examples of the ageing behaviour of interlayer in the literature (Weller et al., 2011). 
The study of these kind of products should be carried out in the design implementation phase in order to validate the durability of the final product before being installed on site.

The procedures of the EN ISO 12543-4:2011 standard are used as a basis to assess the durability of this type of unique solution. This standard contemplates three possible exposures to attacks (high temperature, humidity and ultraviolet radiation) to which the laminated glass product must not present defects or must not vary its luminous transmittance.

\subsection{High Temperature}

In the case of high temperature exposure, test specimens are subjected to $100^{\circ} \mathrm{C}$ in an oven for 16 hours or by immersion in boiling water for 2 hours. In this way, it is checked whether the air between the two glasses was completely eliminated during the lamination process. It is not easy to eliminate this residual air when a metallic or plastic mesh type element is included in the interlayer and depending on its nature.

When this laminated glass is subjected to high temperatures, bubbles may appear in the mesh area. Different tests were carried out with different interlayers and it is easier to laminate this type of material with polyvinyl butyral intercalary. However, on certain occasions this type of interlayer is not suitable as it does not comply with certain mechanical aspects of the project and both the mechanical requirement and the durability must be assessed as a whole.

\subsection{Humidity}
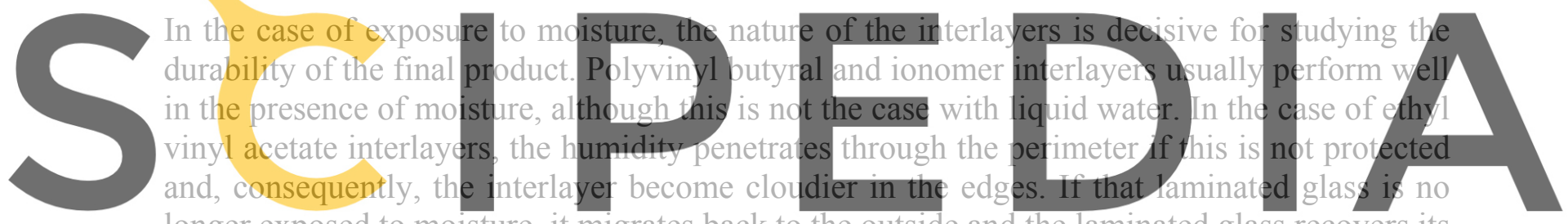

longer exposed to moisture, it migrates back to the outside and the laminated glass recovers its

Register for free at hittps / www.scipedia.com to download the version without the watermark

they react to moisture. The most obvious case is when the material placed between the two glasses is hygroscopic, since if the perimeter is not protected the moisture can migrate to the interior and produce a pathology that leads to lack of adhesion between materials, for example between marble and glass.

\subsection{UV Exposure}

The third attack on laminated glass to verify its durability refers to the ultraviolet exposure for 2,000 hours, after which the variation in luminous transmittance of the test specimens is limited. In this test, defects relating to delamination or bubbles do not usually occur, but the requirement for variation in luminous transmittance may not be met. The durability of laminated glass can also be verified by other standards, but the basis in all is similar. In the case of ANSI Z97.12015 , for example, in addition to limiting the variation in luminous transmittance, the variation in yellowing index, the haze variation and the colour difference is also limited.

If there are additional embedded elements in the laminated glass, it must also be checked that there are no defects in that embedded material or in the interlayer, as it may happen that the two materials work well separately but not together. 
Therefore, it is advisable to determine the variation of luminous reflectance or the variation of the colour coordinates of that embedded material -although the regulations do not contemplate it- in order to fully assess the degradation that the laminated glass is going to suffer.

\section{Conclusions}

- The pathologies of the glass building envelope may be different in nature and due to different causes, but they can be summed up in three main groups: chemical incompatibility, manufacturing failure/error or because of a product is not suitable for its intended use.

- After having analyzed the different cases, the design phase has been identified as the main stage of the building work in which the pathology could be avoided, followed by the product manufacturing phase. Accordingly, architects/project management or product manufacturers are the main agents causing the future pathology or those responsible for it. It should be added that a wrong assembly does not usually generate a pathology but contributes to its manifestation.

As a result, two main remedial actions that can be implemented during the design, construction or maintenance processes are proposed to avoid the generation of pathologies that affect the durability of the building and their user's comfort. On the one hand, testing the selected products taking into account their intended use is the way to

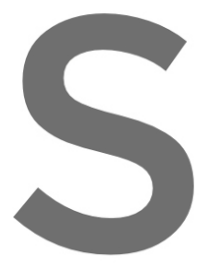
avoid failures before the construction of the building
of the glass building envelope gan be avoided if the du
verified during the des gn phase, gonsidering the type
element will be placed. These previous checks are of p
unique products or solutions, such as laminated giass p
On the other hand, factory production controls became

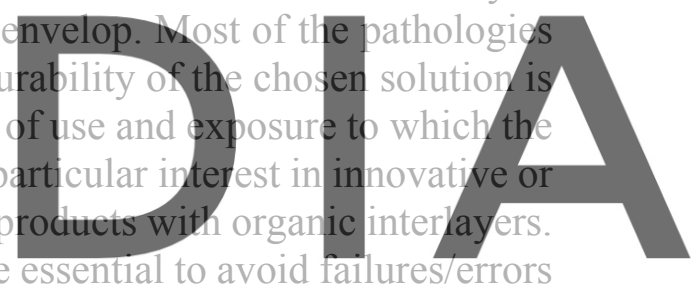
that can occur in the product manufacturing stage.

Register for free at https//wwW.scipedia.com to download the version without the watermark ORCIID

Susana Santamaria-Fernandez: https://orcid.org/0000-0002-0835-4757

Arritokieta Eizaguirre-Iribar: https://orcid.org/0000-0002-5651-9181

Xabier Olano: https://orcid.org/0000-0002-5647-1923

\section{References}

Honfi, D., Reith, A., Vigh, L.G. and Stocker, Gy. (2014). Why glass structures fail? - Learning from failures of glass structures. In Louter, Bos, Belis \& Lebet (Eds), Challenging Glass 4 \& COST Action TU0905 Final Conference. Taylor \& Francis Group, London.

Hubbs, B. and Higgins, J. (2015). Glazing failures and ways to prevent them. In $30^{\text {th }}$ RCI International Convention and Trade Show, 149-160. San Antonio, Texas

Loughran, P. (2003). Falling glass: Problems ans solutions in contemporary architecture. Basel - Boston - Berlin: Birkhäuser - Publishers for Architecture.

Overend, M., De Gaetano, S. and Haldimann, M. (2007). Diagnostic Interpretation of Glass Failure. Structural Engineering International, 17 (2), 151-158.

Sharma, G. (2003). Digital Color Imaging Handbook. Boca Raton - London - New York - Washington, D.C.: CRC Press.

Weller, B. and Kothe, M. (2011). Ageing Behaviour of Polymeric Interlayer Materials and Laminates. In Glass performance days, Conference Proceedings. GDP, Tampere, Finland. 